\title{
Electrical and mechanical responses in the platysma and in the adductor pollicis muscle: in normal subjects
}

\author{
C. KRARUP \\ From the Laboratory of Clinical Neurophysiology, Rigshospital, and the Institute of Neurophysiology, \\ University of Copenhagen, Denmark
}

SUMMARY In the platysma of 34 normal subjects the amplitude of the action potential and twitch tension and tetanic tension were lower, the contraction time of the isometric twitch was 1.4 times shorter, and the potentiation of twitch tension in a staircase and after tetanus was two to four times greater than in $\mathrm{m}$. adductor pollicis. Differences in twitch kinetics and potentiation were related to the four times higher incidence of fast fibres in the platysma than in the adductor pollicis muscle, as determined by histochemistry. Ninety-five per cent confidence limits were established for comparison with patients with myasthenia gravis.

Recordings of the electrical and mechanical responses in myasthenia gravis have hitherto been confined to the intrinsic muscles of the hand, though muscles of the eyes, face, and neck are involved earlier and more severely. This study describes normal findings, electrical and mechanical responses in the platysma to single and repetitive stimuli, and compares them with those obtained in this laboratory by Slomic et al. (1968) in $\mathrm{m}$. adductor pollicis (ADP).

\section{Method}

The platysma was chosen because electrical and mechanical responses to indirect stimuli could be recorded without interference from other muscles, and the inertia of the mass of the muscle and of the recording system was small, allowing the time course and tension of the twitch to be recorded with little distortion. To attain reproducible mechanical recordings, the patient's head was positioned between a steel helmet and a metal clamp on the chin (Fig. 1). The helmet and clamp were fixed to a heavy stand behind a chair, adjustable to fit the position of the head.

\section{STIMULATION}

Rectangular current pulses, $0.2 \mathrm{~ms}$ in duration, were delivered via stainless steel needles, $0.7 \mathrm{~mm}$ in diameter with a $3 \mathrm{~mm}$ bared tip, to the cervical branch of the

Accepted 18 October 1976 facial nerve behind the angle of the jaw (Fig. 1). The cathode was positioned near the nerve by finding a $\overrightarrow{\mathrm{D}}$ 윽 threshold for evoking the muscle action potential of less than $1 \mathrm{~mA}$. The stimulus strength was increased four to six times $(9-20 \mathrm{~mA})$ above the current that elicited a maximal response. Care was taken to ascertain that the stimulus current was maximal throughout the examination.

RECORDING OF ELECTRICAL RESPONSES

The muscle action potential was recorded via stainless steel needles, $0.7 \mathrm{~mm}$ in diameter, inserted subcutaneously for a length of $0.5-1 \mathrm{~cm}$, the stigmatic electrode in the end-plate region $(6-11 \mathrm{~cm}$ from the stimulating cathode) and the remote electrode below the clavicle, $4-15 \mathrm{~cm}$ from the stigmatic electrode (Fig. 1). The electrode impedance was diminished (measured in $0.15 \%$ saline with a potential difference of $2 \mathrm{mV}$ ) by passing an alternating current of $70 \mathrm{~mA}$ for 30 seconds through the electrode in saline at $90^{\circ} \mathrm{C}$ (Buchthal and Rosenfalck, 1966). The impedance was about $1000 \Omega$ for $20-10000 \mathrm{~Hz}$. An earth-electrode was placed between the stimulating and recording electrodes. The pick-up of the remote electrode was less than $1 \%$ of the potential recorded by the stigmatic electrode, seen from recordings between the remote and another still more remote electrode placed on the contralateral shoulder (Fig. 2). The muscle action potential was amplified by an amplifier with a frequency band of $20 \mathrm{~Hz}-10 \mathrm{kHz}, 3 \mathrm{~dB}$ down (DISA, 9014C0101). 

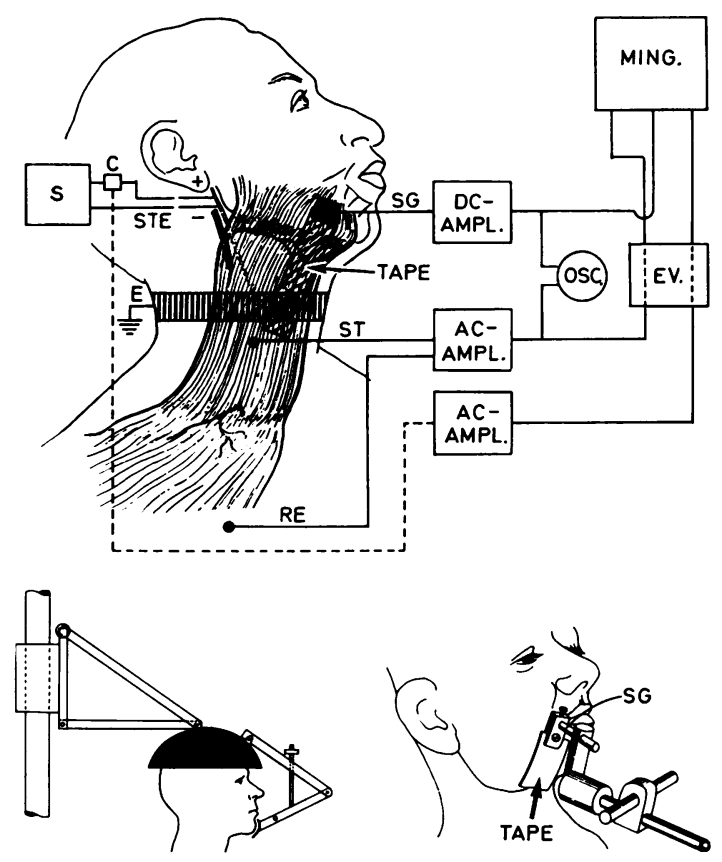

Fig. 1 Apparatus for recording electrical and mechanical responses in the platysma. Below left: fixation of the head between a helmet and a cup on the chin. Above: $S$-stimulator; $S T E$-stimulating electrodes placed along and near the cervical branch of the facial nerve. The stimulating current was recorded via $a$ transformer, $C$, on one channel of the event recorder (EV.) and the ink writer (MING.). ST-stigmatic electrode and $R E$-remote electrode to record the muscle action potentials via the event recorder (EV.) on an ink writer (MING.). The tension of the muscle was measured by a strain gauge, SG (see below right), via inextensible tape and recorded on one channel of the ink writer.

\section{RECORDING OF MECHANICAL RESPONSES}

The tension was measured by a strain gauge (Buchthal and Schmalbruch, 1970) placed on the clamp that kept the chin in position (Fig. 1), via almost inextensible $\operatorname{tape}^{1}$ ( $2 \mathrm{~cm}$ wide, $7-10 \mathrm{~cm}$ long) placed on the skin over the muscle (Fig. 1). The strain gauge was calibrated before and after each examination. The resting load (100-200 g) was adjusted such that the force during contraction was maximal.

STATIC AND DYNAMIC PROPERTIES

A force of less than $1000 \mathrm{~g}$ was recorded without distortion; $1000-1500 \mathrm{~g}$ were measured 5-10\% too small. The total tension was at most $1300 \mathrm{~g}$. A stepchange in length applied in situ was critically damped. The rise time of $3 \mathrm{~ms}$ to $90 \%$ of the peak of the step-

Removed from colostomy bags.
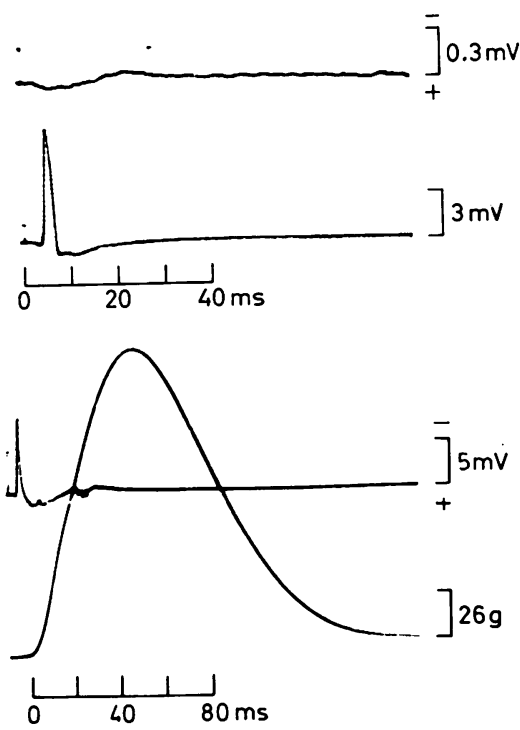

Fig. 2 Above, lower trace: action potential recorded in the end plate region; upper trace: potential recorded between the remote and another still more remote electrode on the contralateral shoulder. Below, upper trace: action potential recorded in the end plate region; lower trace: the isometric twitch.

change was suitable, as the contraction time of the twitch was 35-70 ms (Fig. 2).

The tension was recorded almost isometrically; at a load of $1000 \mathrm{~g}$ the tape that connected the muscle to the strain gauge was stretched at most $10 \%$, and did not yield below a load of $2000 \mathrm{~g}$.

DISPLAY OF RECORDINGS

The time base to record the parameters of the responses was $0.25 \mathrm{~ms} / \mathrm{mm}$ for the latency of the action potential, $0.5 \mathrm{~ms} / \mathrm{mm}$ for the latency of the twitch, and $2 \mathrm{~ms} / \mathrm{mm}$ for the contraction time and the relaxation time. Electrical and mechanical responses and the stimulus current were recorded on a 3channel electromyograph (DISA, 9014B0701), and on a dual beam storage oscilloscope (Tektronix 564), or on an ink jet-writer with an upper limiting frequency of $1000 \mathrm{~Hz}$ (Mingograph, Siemens). The twitch tension was recorded directly, the action potential and the stimulus current by an 'event-recorder' (1000 points, 8 bit) that converted the frequency range from $20-10000 \mathrm{~Hz}$ to $2-1000 \mathrm{~Hz}$ (Dahl and Buchthal, unpublished).

\section{HISTOCHEMISTRY}

Biopsies of the platysma were taken from three males undergoing carotid endarterectomy and who had no symptoms or signs of neuromuscular disease. The 
incidence of fibre types was determined by staining for lactic dehydrogenase and by counterstaining for alpha-glycerophosphate dehydrogenase, and fibres were typed according to Nachmias and Padykula (1958). There were three types, C fibres (rich in mitochondrial and poor in glycolytic enzymes), B fibres (intermediate content of mitochondrial and rich in glycolytic enzymes), and A fibres (poor in mitochondrial and rich in glycolytic enzymes). C fibres correspond to type I fibres (slow fibres, poor in adenosine triphosphatase, ATPase, at $\mathrm{pH}$ 9.4) and $\mathrm{A}$ and B fibres to type IIB and IIA fibres (fast fibres, rich in ATPase at pH 9.4; Brooke and Kaiser, 1970).

\section{TEMPERATURE CONTROL}

The temperature on the skin over the platysma was kept at $36^{\circ} \mathrm{C}$ by an automatically controlled infra-red heating element.

\section{STATISTICAL EVALUATION}

Limits of significance were evaluated by the $t$-test or from cumulative distribution curves (Croxton, 1959).

\section{PROGRAMME OF STIMULATION}

1. Single supramaximal stimuli to determine the time course of electrical and mechanical responses.

2. Trains of stimuli delivered at a rate of $2,3,5$, $10 \mathrm{~s}^{-1}$ for $1.5-3$ seconds with 1-2 minutes between trains.

3. Trains of 1 and $2 s^{-1}$ (platysma) and $2 s^{-1}$ (ADP) for 90 seconds to elicit the staircase phenomenon. After the staircase, single stimuli were given once every half minute for two minutes, and then once every minute for four minutes to ascertain when responses reached resting levels.

4. Tetanic stimuli (20 and $50 \mathrm{~s}^{-1}$ for 1.5 seconds), followed by single stimuli after two, five, 10, 20, 30, 40,50 , and 60 seconds to record post-tetanic facilitation of the action potential and post-tetanic potentiation of twitch tension. Post-tetanic exhaustion (Desmedt, 1966) was evaluated from $3 \mathrm{~s}^{-1}$ trains of stimuli 1.5 seconds in duration, given two, three, four, five, and six minutes after the tetanus.

5. The position of the stimulating cathode was checked by redetermining the threshold current and

Table 1 Fibre types in platysma*

\begin{tabular}{lllll}
\hline & \multicolumn{2}{l}{ Type } & & \\
\cline { 2 - 3 } \cline { 4 - 5 } \cline { 4 - 5 } & $A$ & & \multicolumn{1}{c}{$B$} & $C$ \\
\hline Content of mitochondrial enzymes & Poor & & Intermediate & Rich \\
Number of fibres (total 3549) & 2075 & & 731 & 743 \\
Incidence of fibre types (\%) & 58 & & 21 & 21 \\
Standard deviation (\%) & 8 & & 8 & 4 \\
\hline
\end{tabular}

*Determined by lactic dehydrogenase and counterstained by alphaglycerophosphate dehydrogenase. the current required to elicit a maximal response.

\section{Normal subjects}

Thirty-four subjects, eight females and 26 males, 20-59 years of age, without history, symptoms or signs of neuromuscular disease were examined.

\section{Results}

\section{HISTOCHEMISTRY}

The mean diameter of 3549 fibres from three platysma muscles was $45 \mu \mathrm{m}$ (SD: $16 \mu \mathrm{m}$ ), $25 \%$ smaller than $(\mathrm{P}<0.001)$, and with a larger scatter than in $\mathrm{m}$. biceps brachii (biopsies from four normal males, 2173 fibres, mean: $60 \mu \mathrm{m}$, SD: $10 \mu \mathrm{m}$, Kamieniecka, personal communication). The average diameter of type A fibres was $10-20 \%$ larger than $(\mathrm{P}<0.001)$ that of $\mathrm{B}$ and $\mathrm{C}$ fibres. The incidence of the number of fibres of different type in the platysma is shown in Table 1.

SINGLE STIMULI AND SHORT TRAINS OF STIMULI

In the platysma the amplitude of the action potential, of the twitch tension (P) and of the tetanic tension $\left(\mathrm{P}_{0}\right)$ were lower, the twitch: tetanus ratio $\left(\mathrm{P} / \mathrm{P}_{0}\right)$ was greater, the contraction time (CT) was shorter and the rate of relative force development (in units of tetanic tension, $\mathrm{P} / \mathrm{P}_{0} / \mathrm{CT}$ ) was faster than in the $\mathrm{ADP}$ (Table 2).

Even in normal muscle there may be a small decrement in the size of the action potentials and thee mechanical responses during repetitive stimulation? (Fig. 3). The decrement was similar in the platysma and the ADP, and was less in the electrical than in the mechanical response. The scatter of values from subject to subject was small, the lower $95 \%$ confidence limit for the action potential was $-5-10 \%$, for the twitch tension $-15-25 \%$ below at a stimulus frequency of $5 \mathrm{~s}^{-1}$. At $50 \mathrm{~s}^{-1}$ the variation was large, the $95 \%$ lower confidence limit being $-40 \%$.

\section{POST-TETANIC CHANGES}

The amplitude of the action potential remained constant after the tetanus in the platysma and in the ADP, whereas the increase in twitch tension (post-tetanic potentiation, PTP) was three to four times greater in the platysma than in the ADP $(+85 \pm 8 \%$ compared with $+27 \pm 4 \%$, mean \pm m.e., $P<0.01$, Figs. 3 and 4 ). In both muscles pretetanic tension was attained six to ten minutes after the tetanus. Post-tetanic exhaustion did not occur in the platysma, but was present in two subjects in the ADP.

In both muscles the contraction time was the same in the potentiated twitch as in the twitch before the tetanus. 
Table 2 Responses to single and tetanic stimuli

\begin{tabular}{|c|c|c|c|c|c|c|}
\hline & \multicolumn{3}{|c|}{ Platysma } & \multicolumn{3}{|c|}{ M. Adductor pollicis } \\
\hline & $n$ & Mean & $S D \%$ & $n$ & Mean & $S D \%$ \\
\hline \multicolumn{7}{|l|}{ Electrical response } \\
\hline Amplitude of negative phase (mV) & 28 & $5.3+$ & 38 & 30 & 8.0 & 41 \\
\hline Amplitude of peak-to-peak (mV) & 27 & $6.3 \ddagger$ & 41 & 30 & 14.3 & 39 \\
\hline Latency of muscle action potential (ms) & 29 & 3.2 & 17 & 30 & 2.8 & 11 \\
\hline \multicolumn{7}{|l|}{ Məchanical response } \\
\hline Twitch tension ( $P$ in $\mathbf{g})$ & 34 & $99+$ & 32 & 30 & 470 & 52 \\
\hline Contraction time (CT in $\mathrm{ms}$ ) & 34 & $48 \ddagger$ & 11 & 29 & 65 & 11 \\
\hline Relaxation time (ms) & 34 & $40 \S$ & 11 & 29 & $82 \S$ & 13 \\
\hline Latency of the twitch (ms) & 34 & 7.6 & 14 & 29 & 8.8 & 13 \\
\hline Rate relat. force develop. $\left(\mathrm{P} / \mathrm{P}_{0} / \mathrm{CT}\right)$ & 31 & $2.8 \pm$ & 26 & 23 & 1.4 & 36 \\
\hline Twitch: tetanus ratio $\left(\mathrm{P} / \mathrm{P}_{0}\right)$ & 31 & $0.13 \ddagger$ & 25 & 23 & 0.09 & 32 \\
\hline Tetanic tension $\left(P_{0}\right.$ in $\left.g\right)$ & 31 & $707 \ddagger$ & 28 & 23 & 4570 & 25 \\
\hline
\end{tabular}

$n$ : number of subjects.

$\mathrm{SD} \%$ : the SD from subject to subject in per cent of the mean.

§Half relaxation time measured in the platysma, three-fourth relaxation time in the ADP.

St atistical differences: ${ }^{*} P<0.05,+P<0.01,{ }_{P}<0.001$ from subject to subject in the platysma and the ADP.

Normal values in the ADP from Slomic et al. (1968).

The SD, within the subject, of the amplitude of the action potential and the twitch tension was $8 \%$ and $13 \%$ in the platysma and $2 \%$ and $8 \%$ in the ADP; of the contraction time it was $4 \%$.

$2 / \mathrm{s}$ for $3 \mathrm{~s}$

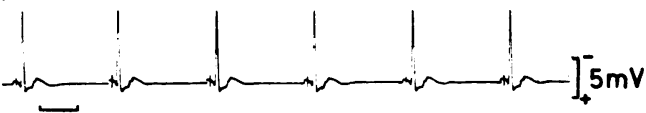

$20 \mathrm{~ms}$

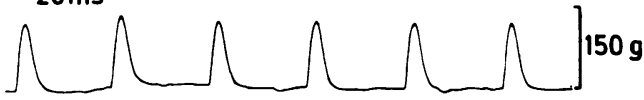

$200 \mathrm{~ms}$

$3 / s$ for $3 s$
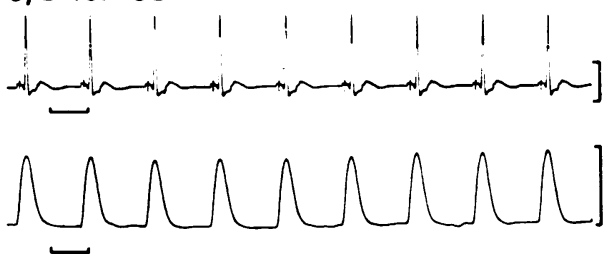

$5 / \mathrm{s}$ for $11 / 2 \mathrm{~s}$
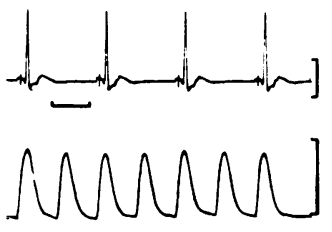

$10 / \mathrm{s}$ for $1 \frac{1}{2} \mathrm{~s}$

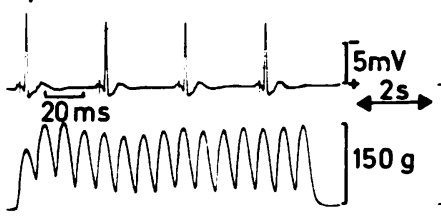

$\overleftarrow{200 \mathrm{~ms}}$

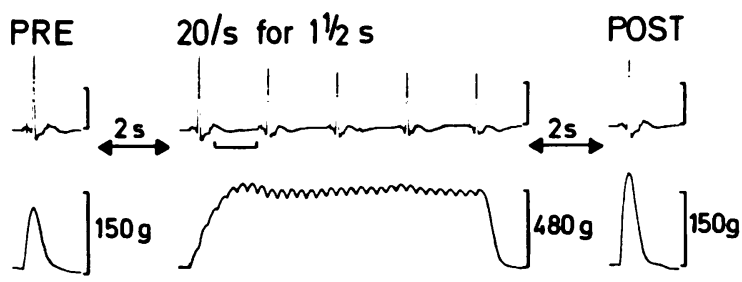

PRE $\quad 50 / \mathrm{s}$ for $11 / 2 \mathrm{~s}$<smiles>CCCCCCCCCCCCCCC</smiles>

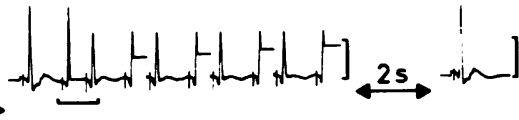

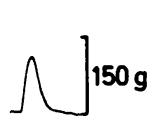

POST

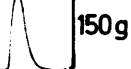

$200 \mathrm{~ms}$ 


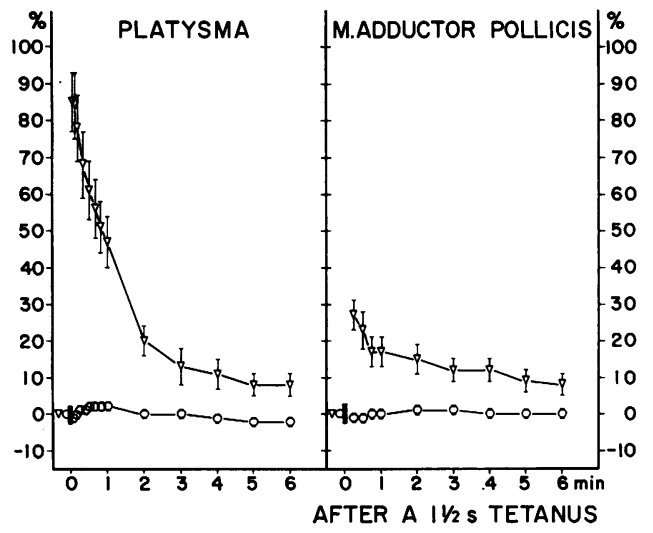

Fig. 4 Post-tetanic potentiation in the platysma and the ADP as a function of time after a tetanus (50 stimuli per second for 1.5 seconds, I end of tetanus) in per cent of the pretetanic responses. $\nabla$ twitch tension. $O$ action potential. The vertical bars denote the mean error.

Data from the ADP are taken from Slomic et al. (1968).

\section{STAIRCASE PHENOMENON}

The amplitude of the action potential remained unchanged in the platysma and in the ADP (Fig. 6).

At a stimulus frequency of $2 \mathrm{~s}^{-1}$ the staircase was twice as large in the platysma as in the ADP $(+88 \pm 9 \%$ compared with $+42 \pm 5 \%$, mean \pm m.e., $P<0.01$, Fig. 6). Maximum potentiation reached peak at 40 seconds in the platysma as compared with 90 seconds in the ADP. In the platysma the staircase increased with increasing frequency of stimulus (Fig. 5), it was

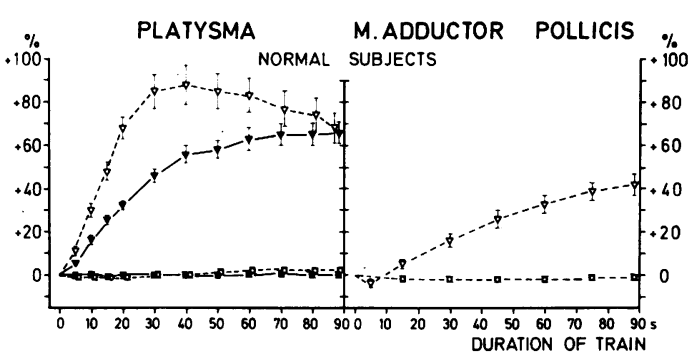

Fig. 6 Percentage increase in twitch tension $(\nabla, \nabla)$ during a staircase in the platysma $\left(2 s^{-1}\right.$, open symbols and $1 s^{-1}$, solid symbols) and in the ADP $\left(2 s^{-1}\right) . \circ$, $\bullet$ : action potential. The vertical bars denote the mean error. Data from the ADP are taken from Slomic et al. (1968).

$25 \%$ larger when 80 stimuli were given at $2 \mathrm{~s}^{-1}$ than at $1 \mathrm{~s}^{-1}(\mathrm{P}<0.05$, Fig. 6), whereas it depended on the number of stimuli rather than on the frequency in the ADP (Slomić et al., 1968). With a stimulus frequency of $2 s^{-1}$ in the platysma but not in the ADP, the twitch decreased again after potentiation was maximal (Figs. 5 and 6). During the staircase the con-o traction time remained unchanged in the platysma whereas it decreased by $10 \%$ in the ADP. The relaxa? tion time decreased by $10 \%(\mathrm{P}<0.05)$ in the platysma and in the ADP, when potentiation was maximal.

\section{POSTSTAIRCASE RESPONSES IN PLATYSMA}

After the 1 and $2 \mathrm{~s}^{-1}$ staircases for 90 seconds the action potential remained unchanged (Figs. 5 and 7 ) Although potentiation at the end of the staircases of

STAIRCASE

AFTER STAIRCASE

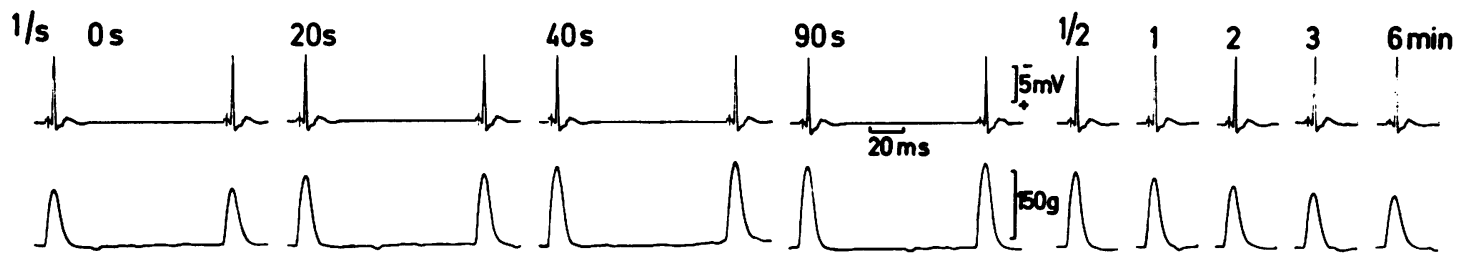

$\widetilde{200} \mathrm{~ms}$

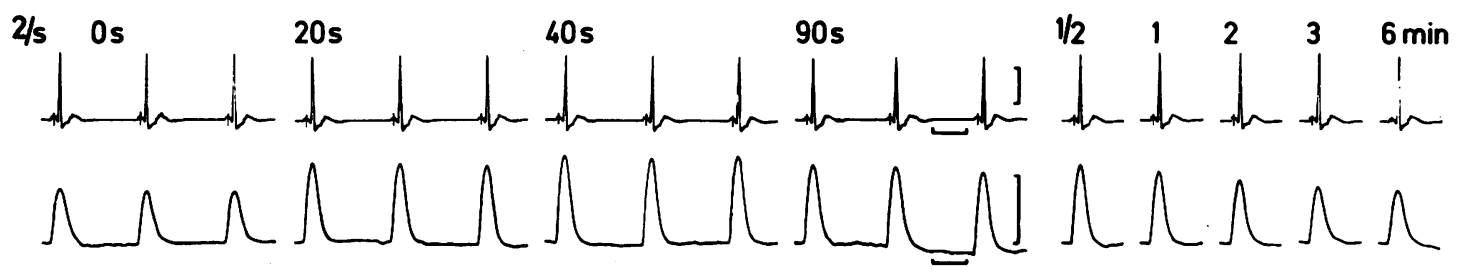

Fig. 5 Electrical (upper traces) and mechanical (lower traces) responses in the platysma during and after a staircase of 90 seconds (above, $1 s^{-1}$; below, $2 s^{-1}$ ). Thirty-five year old man without history, symptoms, or signs of neuromuscular disease. 


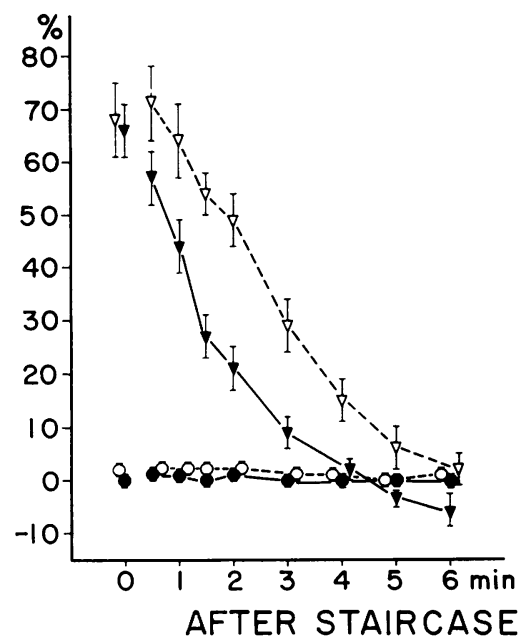

Fig. 7 Increase in twitch tension $(\nabla, \nabla)$ as a function of time after the staircase. Time zero denotes the end of the staircase. After $2 s^{-1}$ staircase for 90 seconds, open symbols and after $1 \mathrm{~s}^{-1}$ staircase for 90 seconds, solid symbols. $\bigcirc, \bullet:$ action potential. The vertical bars denote the mean error.

both frequencies was the same (Fig. 7), the twitch was $15 \%$ more potentiated half a minute after the $2 \mathrm{~s}^{-1}$ than the $1 \mathrm{~s}^{-1}$ staircase (Fig. 7). Resting levels were attained at both frequencies six minutes after the staircase (Figs. 5 and 7).

\section{Discussion}

The main advantage in recording from the platysma was that electrical and mechanical responses could be recorded from a proximal muscle without interference from other muscles when needle electrodes with a $3 \mathrm{~mm}$ bared tip were used to stimulate the nerve.

For anatomical reasons rigid fixation of the platysma was more difficult than of the ADP, reflected in the larger scatter of amplitudes of electrical and mechanical responses in the same patient (Table 2). The variation in amplitude during trains of stimuli was the same as in the ADP and was smaller in the electrical than in the mechanical responses. The variation was small during slow rates of stimuli, but increased above $5 \mathrm{~s}^{-1}$. At $50 \mathrm{~s}^{-1}$ a decrease in the action potential and the mechanical response of about $40 \%$ because of movement artefact was within limits of normal.

The contraction time of the whole platysma was as short as that of small bundles of the muscle (Buchthal and Schmalbruch, 1970), consistent with the large proportion of fast fibres in the muscle $(80 \%$ type II fibres). Conversely, the ADP had a $40 \%$ longer contraction time and contained only $20 \%$ of fibres of type II (fast fibres, Johnson et al., 1973).

The difference in incidence of fibre types is also consistent with the greater potentiation of twitch tension in the platysma than in the ADP, since potentiation is confined to fast twitch fibres (Close and Hoh (1968) and Hanson (1974) in rat muscle; Bagust et al. (1974) in cat muscle).

Opinions differ as to the mechanism of potentiation of twitch tension: Ritchie and Wilkie (1955) measured a prolongation of the active state in PTP in frog muscle at $0^{\circ} \mathrm{C}$; Desmedt and Hainaut (1968) believed it to be caused by intensification of the active state, in that the contraction time was shortened in the potentiated twitch of the ADP. The shortened contraction time seems to be a poor gauge of intensification of the active state, as it remained unchanged in the much more potentiated platysma. Similarly, large potentiation was associated with slight or no changes in contraction time in single muscle fibres of frog (Colomo and Rocchi, 1965), and in rat muscle (Close and Hoh, 1968). Rosenfalck (1974) calculated the active state to be intensified during potentiation of the twitch, and more so in the platysma than in the ADP.

Unlike findings in the ADP, the staircase phenomenon in the platysma increased with the frequency of stimulation rather than with the number of stimuli.
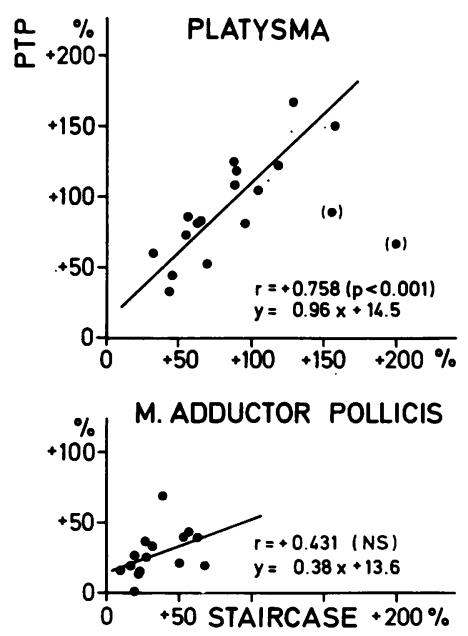

Fig. 8 Maximal post-tetanic potentiation (PTP, ordinate) as a function of the maximal potentiation of twitch tension in a staircase $\left(2 s^{-1}\right.$, abscissa) in normal subjects. Symbols in parentheses were included in the calculation of the correlation coefficient but omitted in the calculation of the equation of the relation. In the $A D P$ the relation was not significant (NS). 
Similarly, twitch potentiation was $20 \%$ larger $(P<0.05)$ two seconds after 30 stimuli delivered at a ate of $20 \mathrm{~s}^{-1}$ (PTP), than in a staircase of $2 \mathrm{~s}^{-1}$ after 30 stimuli. On the other hand, potentiation was the same when 80 stimuli were given in a staircase $\left(2 s^{-1}\right)$ as two seconds after a tetanus of $50 \mathrm{~s}^{-1}$ (80 stimuli), suggesting that potentiation had reached maximum under both conditions.

Maximum potentiation differed in different subjects, but in the platysma it was the same after a tetanus as during a staircase, suggesting that the mechanism of potentiation was the same under both conditions (Fig. 8).

In the platysma and in the ADP, the action potential remained unchanged after tetanus, presumably because all fibres were activated by supramaximal stimuli. In only one normal subject was there a slight transient block in the action potential after tetanus.

\section{References}

Bagust, J., Lewis, D. M., and Luck, J. C. (1974). Posttetanic effects in motor units of fast and slow twitch muscle of the cat. Journal of Physiology (Lond.), 237, 115-121.

Brooke, M. H., and Kaiser, K. K. (1970). Muscle fiber types: how many and what kind? Archives of Neurology (Chic.), 23, 369-379.

Buchthal, F., and Rosenfalck, A. (1966). Evoked action potentials and conduction velocity in human sensory nerves. Brain Research, 3, 1-122.

Buchthal, F., and Schmalbruch, H. (1970). Contraction times and fibre types in intact human muscle. Acta Physiologica Scandinavica, 79, 435-452.

Close, R., and Hoh, J. F. Y. (1968). The after-effects of repetitive stimulation on the isometric twitch contraction of rat fast skeletal muscle. Journal of Physiology (Lond.), 197, 461-477.

Colomo, F., and Rocchi, P. (1965). Staircase effect and post-tetanic potentiation in frog nerve-single muscle fibre preparations. Archivio di Fisiologia (Firenze), 64, 189-266.

Croxton, F. E. (1959). Elementary Statistics, pp. 376. Dove Publications: New York.

Desmedt, J. E. (1966). Presynaptic mechanism in myasthenia gravis. Annals of the New York Academy of Sciences, 135, 209-246.

Desmedt, J. E., and Hainaut, K. (1968). Kinetics of myofilament activation in potentiated contraction: staircase phenomenon in human skeletal muscle. Nature, 217, 529-532.

Hanson, J. (1974). The effects of repetitive stimulation on the action potential and the twitch of rat muscle. Acta Physiologica Scandinavica, 90, 387-400.

Johnson, M. A., Polgar, J., Weightman, D., and Appleton, D. (1973). Data on the distribution of fibre types in thirty-six human muscles. An autopsy study. Journal of the Neurological Sciences, 18, 111-129.

Nachmias, V. T., and Padykula, H. A. (1958). A histochemical study of normal and denervated red and white muscle of the rat. Journal of Biophysical and Biochemical Cytology, 4, 47-54.

Ritchie, J. M., and Wilkie, D. R. (1955). The effect of previous stimulation on the active state of muscle. $\frac{\text { ते }}{2}$ 을 Journal of Physiology (Lond.), 130, 488-496.

Rosenfalck, P. (1974). Change in active state during the staircase phenomenon of human muscle. Acta Phy-O siologica Scandinavica, 92, 12-20.

Slomić, A., Rosenfalck, A., and Buchthal, F. (1968). Electrical and mechanical responses of normal and myasthenic muscle-with particular reference to the staircase phenomenon. Brain Research, 10, 1-78. 